\title{
Exposure to electromagnetic fields and suicide among electric utility workers: a nested case-control study
}

\author{
Edwin van Wijngaarden, David A Savitz, Robert C Kleckner, Jianwen Cai, Dana Loomis
}

\begin{abstract}
Objectives-This nested case-control study examines mortality from suicide in relation to estimated exposure to extremely low frequency electromagnetic fields (EMFs) in a cohort of 138905 male electric utility workers.

Methods-Case-control sampling included 536 deaths from suicide and 5348 eligible controls. Exposure was classified based on work in the most common jobs with increased exposure to magnetic fields and indices of cumulative exposure to magnetic fields based on a measurement survey.

Results-Suicide mortality was increased relative to work in exposed jobs and with indices of exposure to magnetic fields. Increased odds ratios (ORs) were found for years of employment as an electrician (OR $2.18 ; 95 \%$ confidence interval $(95 \%$ CI) 1.25 to 3.80 ) or lineman (OR $1.59 ; 95 \%$ CI 1.18 to 2.14), whereas a decreased OR was found for power plant operators (OR $0.67 ; 95 \%$ CI 0.33 to 1.40 ). A dose response gradient with exposure to magnetic fields was found for exposure in the previous year, with a mortality OR of 1.70 (95\% CI 1.00 to 2.90 ) in the highest exposure category. Stronger associations, with ORs in the range of $2.12-3.62$, were found for men $<50$ years of age.

Conclusion-These data provide evidence for an association between occupational electromagnetic fields and suicide that warrants further evaluation. A plausible mechanism related to melatonin and depression provides a direction for additional laboratory research as well as epidemiological evaluation.

(Occup Environ Med 2000;57:258-263)
\end{abstract}

Keywords: electromagnetic fields; suicide; nested casecontrol

In the United States, suicide is currently the eighth leading cause of death ${ }^{1}$ and is, with homicide, the third leading cause of years of potential life lost. ${ }^{2}$ Although suicide rates showed a steady increase from the mid-1950s to the late 1970 s, there has been relatively little change over the past 15 years. Mental and addictive disorders are the key risk factors for suicide and suicidal behaviour. ${ }^{3}$ Analyses of patterns and trends of suicide in the United States show increased risks among men, white people, divorced, widowed, and elderly people, and those living in western states. ${ }^{34}$
The potential for an association between extremely low frequency electromagnetic fields (EMFs) and suicide is biologically plausible. Wilson ${ }^{5}$ has postulated a link between exposure to EMFs and depression, based on observations that these exposures alter the daily rhythm of pineal melatonin production and excretion in rats. A pathway involving the effect of EMFs on the production of melatonin, the role of melatonin in depression, and depression as an important risk factor for suicidal behaviour points to suicide as a potential consequence of exposure to EMFs. Although data concerning the effects of exposure to EMFs on human pineal function are limited, inhibition of melatonin production has been reported. ${ }^{6-8}$ Furthermore, several reports have found that lower levels of melatonin formation are associated with depression. ${ }^{9-12}$ Moreover, exposure to EMFs has been linked with depression and depressive tendencies. ${ }^{13-18}$ Finally, there is strong evidence that depressive illness is an important risk factor for suicide. ${ }^{34}$

We conducted a case-control study to consider the risk of suicide for electric utility workers for whom individual estimates of exposure to magnetic fields were obtained based on job titles. The study population of 5884 subjects was obtained from a cohort of 138905 men in the original mortality study. ${ }^{19}$ Knowledge about the relation between exposure to magnetic fields and suicide is extended through the analysis by time windows, distinguishing possible acute and chronic effects of exposure. Also, analyses were performed for separate age categories. People in different age categories may be more or less vulnerable to the effects of exposure to EMFs as the nature of depression seems to change with age. ${ }^{2021}$

\section{Methods}

DESIGN AND STUDY POPULATION

Details of the cohort identification have been published in detail ${ }^{19}$ and are briefly described here. Eligible workers were employed full time at any of five electric power companies in the United States at any time between 1 January 1950 and 31 December 1986, with a total of at least 6 months of continuous employment. Women were excluded because they rarely worked in jobs with the exposure of interest. After exclusions due to lack of availability of records before 1 September 1954 and 1 January 1955 at two of the companies, missing date of birth, unknown start dates, and other errors in the records, 138905 workers were included in the cohort.

The case-control sampling from the original cohort included all 536 deaths from suicide 
(eighth revision of the international classification of diseases (ICD-8) and ICD-9: E950959) as well as 5348 eligible controls. Controls were selected with risk set sampling. ${ }^{22}$ For each suicide case, workers in the cohort who were alive on the date of death of the case, and who had the same birth year and ethnicity were matched. If fewer than 10 eligible controls were available for the case then all eligible controls were selected; otherwise 10 were randomly chosen. This selection procedure generated for each case a set of controls that provided an estimate of the population distribution of exposure at the time of the case's death. ${ }^{23}$

ASSIGNMENT OF EXPOSURE TO MAGNETIC FIELDS Workers in the electric utility industry experience complicated patterns of exposure to $\mathrm{EMFs}$, with potentially several measurements including transient measures of magnetic and electric fields. ${ }^{24}$ Exposure to EMFs was estimated by assessment of exposure to magnetic fields, focusing on the time weighted average (TWA), as described in detail elsewhere ${ }^{1926-28}$ and is briefly summarised here.

Complete work histories were abstracted and computerised. To consolidate thousands of job titles at the five participating companies, 28 occupational categories were constructed based on work activities, responsibilities, and exposure potential, ${ }^{26}$ to define the rows of a job exposure matrix. Within the occupational categories, 1060 distinct job titles were monitored. Randomly selected workers wore a personal average magnetic exposure (AMEX) meter (Enertech Consultants, Campbell, CA, USA) that recorded the time integrated mean exposure to magnetic fields over the work shift. A total of 2842 usable measurements was obtained and used to compute TWA exposures and arithmetic means for each occupational category in the job exposure matrix (JEM).27 28 Cells for exposure to magnetic fields were rank ordered and collapsed into five groups to increase statistical precision. Grouping was based on the distribution of the arithmetic mean exposure of each occupational category measured successfully in each company. The $25,50,75$, and 87.5 percentiles were chosen as arbitrary cut off points to arrive at five groups (5 level JEM), with average TWA exposures of $0.12,0.21,0.39,0.62$, and $1.27 \mu \mathrm{T}$. Each of the combinations of company and occupational category was placed in one of the five levels of the JEM according to estimated level of exposure to magnetic fields. ${ }^{28}$ The average group exposures were assigned for each occupational category and summed over employment intervals for each worker. The mean exposures in each calendar year were summed and multiplied by the proportion of all hours spent at work (0.23) to yield workday exposure in $\mu \mathrm{T}$-days and divided by 365 to yield $\mu \mathrm{T}$-years of occupational exposure. ${ }^{19}$

CONFOUNDING FACTORS

Established risk factors for suicide are history of mental and addictive disorders, abnormalities and alterations in the serotonin system, and disrupted family environment. ${ }^{3}$ However, information on these confounding factors was not available from personnel records at the companies. Socioeconomic status, ${ }^{29}{ }^{30}$ solvent exposure, ${ }^{31}$ decreased exposure to sunlight, ${ }^{32-34}$ and living in the western United States ${ }^{3}{ }^{4}$ are possible risk factors for suicide and were taken into account in this study. Workers were classified into four categories of social class: upper white collar, lower white collar, skilled blue collar, and unskilled blue collar workers. Potential exposure to solvents was assessed by expert panels at each of the five participating companies. Solvents were used as thinners, degreasers, cleaners, and lubricants, and included 1,1,1-trichloroethane, acetone, carbon tetrachloride, and Varsol. Workers were classified as unexposed to an agent up to the time when they entered a job with exposure potential, and they remained classified as exposed thereafter. ${ }^{19} 35$ For exposure to sunlight, workers were classified in a similar manner. Panels classified each job as involving primarily indoor or primarily outdoor work. Information on occupational exposure to sunlight was collected only at the three largest companies; therefore exposures at the two smaller ones were estimated. ${ }^{35}$ The five participating electric utility companies were divided into two groups, depending on their location in the United States. One company was situated in the western United States, whereas the other companies were in the eastern United States.

\section{DATA ANALYSIS}

Firstly, the association with exposure to magnetic fields was investigated using occupational categories. Suicide risks were considered for electricians, linemen, and power plant operators, the three most common jobs with increased exposure to magnetic fields among the five utility companies. ${ }^{19}$ Risk estimates were calculated for men in those occupations during the calendar year of death, ever employed as such in the 1-5 year period before death, and for men with the specific occupations as the longest held job throughout their career. The reference group consisted of those not employed in the category of interest in the specific time intervals.

As well as the analyses with occupational categories, risk estimates were assessed based on time integrated exposure. Cumulative exposure ( $\mu$ T-year) in the calendar year before the year of death (past 1-2 years) was considered recent exposure. Total exposure was assessed as career exposure for cases and cumulative exposure up to the date of death of the matching case for controls. Furthermore, cumulative exposure was examined in four time intervals: past $1-5$ years before death, past 5-10 years before death, past 10-20 years before death and $\geqslant 20$ years before death. The time windows were chosen to consider possible latency of the effect of exposure to magnetic fields on suicide.

For recent and total exposure as well as for each of the four time windows, exposure categories were created based on percentiles of exposure of cases, ensuring an equitable distribution of deaths across categories. For acute 
Table 1 Crude conditional logistic regression ORs (95\% CIs) for suicide relative to potential risk factors

\begin{tabular}{|c|c|c|c|c|c|}
\hline \multirow[b]{2}{*}{ Risk factor } & \multicolumn{2}{|c|}{ Controls } & \multicolumn{2}{|c|}{ Cases } & \multirow[b]{2}{*}{ OR $(95 \% C I)$} \\
\hline & $n$ & $(\%)$ & $n$ & $(\%)$ & \\
\hline \multicolumn{6}{|l|}{ Work: } \\
\hline In work & 2865 & 93.0 & 215 & 7.0 & 1.00 \\
\hline Out of work & 2483 & 88.6 & 321 & 11.5 & $2.15(1.75$ to 2.66$)$ \\
\hline \multicolumn{6}{|l|}{ Social class: } \\
\hline Upper white & 728 & 91.9 & 64 & 8.1 & 1.00 \\
\hline Lower white & 771 & 90.0 & 86 & 10.0 & $1.27(0.91$ to 1.78$)$ \\
\hline Skilled blue & 2069 & 90.5 & 217 & 9.5 & $1.19(0.89$ to 1.59$)$ \\
\hline Unskilled blue & 1780 & 91.3 & 169 & 8.7 & $1.07(0.79$ to 1.46$)$ \\
\hline \multicolumn{6}{|c|}{ Exposure to solvents: } \\
\hline No & 1483 & 91.0 & 146 & 9.0 & 1.00 \\
\hline Yes & 3865 & 90.8 & 390 & 9.2 & $1.03(0.84$ to 1.25$)$ \\
\hline \multicolumn{6}{|c|}{ Exposure to sunlight: } \\
\hline No & 2824 & 91.8 & 254 & 8.3 & 1.00 \\
\hline Yes & 2524 & 90.0 & 282 & 10.1 & $1.25(1.04$ to 1.50$)$ \\
\hline \multicolumn{6}{|l|}{ Location in USA: } \\
\hline East & 3251 & 60.8 & 272 & 50.7 & 1.00 \\
\hline West & 2097 & 39.2 & 264 & 49.3 & $1.56(1.30$ to 1.89$)$ \\
\hline
\end{tabular}

exposure and the four windows, zero exposure was chosen as the referent category (men who were not employed in the relevant time window) and compared with men in quartiles of that distribution. For chronic exposure, men below the 25 th percentile formed the referent category, with the other percentiles defined as $25-49,50-74,75-89$, and $\geqslant 90$. Suicide risk was also evaluated among men in three different age categories (age $<34,35-49$ and $\geqslant 50$ ). Here also, zero dose was chosen as referent category and compared with men in percentiles $>0-49$ and $\geqslant 50$, based on distribution of exposure of cases.

Adjusted odds ratios (ORs) (estimated rate ratios) and $95 \%$ confidence intervals (95\% CIs) were derived from conditional logistical regression models with the PHREG procedure with SAS system software PC version 6.12 (SAS Institute, Cary, NC, USA). These analyses were conditioned on the matching factors birth year and ethnicity. Work status, reflecting whether a worker was or was not employed in a given year of death, was included in the model to control for the healthy worker effect, ${ }^{36}$ which was important for the outcome of suicide. For consistency, social class, location of company, exposure to solvents, and exposure to sunlight were also included in the model, although little confounding by these variables was found.

\section{Results}

Mortality from suicide was similar to overall mortality in the original cohort ${ }^{19}$ with respect to race and calendar year. Nearly $87 \%$ of the men who committed suicide were white, and most deaths occurred in 1980-8. The average duration of work was 16.2 years with an SD of 9.8. Nevertheless, compared with the overall mortality in the original cohort, the age distribution of suicide deaths was quite different. The average age of the cases was quite low: 49 years, ranging from 19 to 93 . Fifty three per cent of all suicide deaths occurred before the age of 50 . Of the 3502 deaths in this age group in the original cohort, $286(8 \%)$ were due to suicide.

Table 1 presents ORs for potential risk factors of suicide available in this study. Being out of work, exposure to sunlight, and location in the western United States were all associated with suicide. Men who were out of work had about a twofold increased risk of committing suicide compared with active workers. Exposure to sunlight at the workplace seemed to have a modestly increased risk of suicide (OR 1.25 ; $95 \%$ CI 1.04 to 1.50 ). Workers living in the western United States were found to have an OR of 1.56 (95\% CI 1.30 to 1.89 ). Social class and exposure to solvents were not related to suicide.

Table 2 shows the risk of suicide among men working as an electrician, lineman, or power plant operator at three different periods: during the calendar year of death, during 1-5 years previously, and throughout a career. Increased risks were found for employment as an electrician in all three periods, strongest for the most recent periods. Employment as a lineman also showed increased risk, but not in the past year. Employment as power plant operator was weakly inversely associated with suicide.

Table 3 shows the risk estimates for suicide relative to cumulative exposure to magnetic fields in several time frames. There was a monotonic dose-response gradient with recent exposure as a categorical measure, with an OR of 1.70 (95\% CI 1.00 to 2.90$)$ in the highest interval. For cumulative exposure in the past 1-5 years before death, the categorical analysis yielded ORs of 1.12-1.53. Although the doseresponse gradient was inconsistent, the highest risk was found in the highest exposure group. For the other windows of exposure, ORs close to or below the null were found, providing no indication of increased risks. A weak inverse gradient in risk with increasing exposure was found for cumulative exposure $\geqslant 20$ years before death. For total exposure, increased ORs were found for all levels above the referent, but there was no dose-response pattern.

Table 2 Adjusted ${ }^{\star}$ conditional regression ORs (95\% CIs) for suicide relative to type or duration of work in selected occupations

\begin{tabular}{|c|c|c|c|c|c|c|c|c|c|}
\hline \multirow{2}{*}{$\begin{array}{l}\text { Time of } \\
\text { employment }\end{array}$} & \multicolumn{3}{|c|}{ Electrician } & \multicolumn{3}{|c|}{ Lineman } & \multicolumn{3}{|c|}{ Power plant operator } \\
\hline & Cases & Controls & OR $(95 \% C I)$ & Cases & Controls & OR $(95 \% C I)$ & Cases & Controls & OR $(95 \% C I)$ \\
\hline \multicolumn{10}{|l|}{ Past year: } \\
\hline No & 520 & 5235 & 1.00 & 509 & 5051 & 1.00 & 528 & 5176 & 1.00 \\
\hline Yes & 16 & 113 & $2.18(1.25$ to 3.80$)$ & 27 & 297 & 0.98 (0.63 to 1.54$)$ & 8 & 172 & $0.67(0.33$ to 1.40$)$ \\
\hline \multicolumn{10}{|l|}{ Past $1-5 \mathrm{y}$ : } \\
\hline No & 514 & 5186 & 1.00 & 485 & 4955 & 1.00 & 522 & 5102 & 1.00 \\
\hline Yes & 22 & 162 & 1.84 (1.15 to 2.94$)$ & 51 & 393 & 1.43 (1.01 to 2.05$)$ & 14 & 246 & $0.71(0.41$ to 1.25$)$ \\
\hline \multicolumn{10}{|l|}{ Career: } \\
\hline No & 509 & 5148 & 1.00 & 441 & 4731 & 1.00 & 516 & 5022 & 1.00 \\
\hline Yes & 27 & 200 & $1.59(1.04$ to 2.45$)$ & 95 & 617 & $1.59(1.18$ to 2.14$)$ & 20 & 326 & $0.69(0.43$ to 1.11$)$ \\
\hline
\end{tabular}

${ }^{\star}$ Adjusted for the effects of work (active or out of work), social class, location in USA (east or west), exposure to solvents and sunlight

†Past year=employment at calendar year of death; past $1-5 \mathrm{y}=$ ever employed $1-5$ years before death; career=longest held job throughout career. 


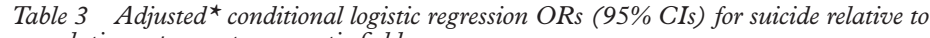
cumulative exposure to magnetic fields

\begin{tabular}{|c|c|c|c|}
\hline Exposure level ( $\mu$ T-years) & Cases & Controls & $O R(95 \% C I)$ \\
\hline \multicolumn{4}{|l|}{ Recent exposure: } \\
\hline 0 & 294 & 2353 & 1.00 \\
\hline$>0-0.029$ & 58 & 796 & $1.19(0.75$ to 1.89$)$ \\
\hline $0.03-0.049$ & 62 & 811 & $1.41(0.85$ to 2.34$)$ \\
\hline $0.05-0.11$ & 62 & 719 & $1.63(0.97$ to 2.71$)$ \\
\hline$\geqslant 0.12$ & 60 & 669 & $1.70(1.00$ to 2.90$)$ \\
\hline \multicolumn{4}{|l|}{ Past $1-5 \mathrm{y}$ : } \\
\hline 0 & 222 & 1857 & 1.00 \\
\hline$>0-0.10$ & 75 & 624 & $1.25(0.90$ to 1.75$)$ \\
\hline $0.11-0.19$ & 95 & 1338 & $1.12(0.76$ to 1.64$)$ \\
\hline $0.20-0.35$ & 73 & 792 & $1.45(0.97$ to 2.17$)$ \\
\hline$\geqslant 0.36$ & 71 & 737 & $1.53(1.01$ to 2.31$)$ \\
\hline \multicolumn{4}{|l|}{ Past $5-10 \mathrm{y}$ : } \\
\hline 0 & 202 & 1688 & 1.00 \\
\hline$>0-0.13$ & 101 & 1254 & $0.71(0.53$ to 0.95$)$ \\
\hline $0.14-0.24$ & 89 & 861 & $1.01(0.74$ to 1.39$)$ \\
\hline $0.25-0.43$ & 42 & 450 & $0.91(0.62$ to 1.33$)$ \\
\hline$\geqslant 0.44$ & 102 & 1095 & $1.00(0.73$ to 1.38$)$ \\
\hline \multicolumn{4}{|l|}{ Past $10-20$ y: } \\
\hline 0 & 157 & 1683 & 1.00 \\
\hline$>0-0.13$ & 93 & 772 & $1.09(0.78$ to 1.53$)$ \\
\hline $0.14-0.32$ & 98 & 909 & $1.14(0.82$ to 1.61$)$ \\
\hline $0.33-0.69$ & 94 & 943 & $1.09(0.77$ to 1.55$)$ \\
\hline$\geqslant 0.70$ & 94 & 1041 & 1.05 (0.73 to 1.53$)$ \\
\hline \multicolumn{4}{|l|}{ Past $>20$ y: } \\
\hline 0 & 314 & 3044 & 1.00 \\
\hline$>0-0.18$ & 57 & 522 & $0.91(0.59$ to 1.41$)$ \\
\hline $0.19-0.43$ & 54 & 460 & $0.96(0.60$ to 1.53$)$ \\
\hline $0.44-1.04$ & 55 & 588 & $0.81(0.50$ to 1.30$)$ \\
\hline$\geqslant 1.05$ & 56 & 734 & $0.72(0.42$ to 1.21$)$ \\
\hline \multicolumn{4}{|l|}{ Total exposure: } \\
\hline$<0.25$ & 133 & 1181 & 1.00 \\
\hline $0.25-0.64$ & 135 & 1212 & $1.26(0.96$ to 1.67$)$ \\
\hline $0.65-1.54$ & 134 & 1474 & $1.13(0.83$ to 1.53$)$ \\
\hline $1.55-3.00$ & 79 & 888 & $1.20(0.83$ to 1.71$)$ \\
\hline$\geqslant 3.01$ & 55 & 593 & $1.33(0.89$ to 2.01$)$ \\
\hline
\end{tabular}

^Adjusted for the effects of work (active or out of work), social class, location in USA (east or west), and exposure to solvents and sunlight.

Men <50 years old with recent exposure above the median had notably increased ORs; 2.39 (95\% CI 1.00 to 5.69) for men aged $<35$ and 3.62 (95\% CI 1.41-9.29) for men aged $35-49$ (table 4 ). Men aged $\geqslant 50$ had ORs $<1$, but this group included retired workers without recent exposure. However, restricting the analysis to men aged $50-66$ provided similar results. The ORs were lower for cumulative exposure in the period 1-5 years before death, with an increased risk for men aged 35-49 (OR $2.19 ; 95 \%$ CI 1.12 to 4.28 ). Analyses for other exposure windows generally yielded ORs close to or $<1$ (data not shown).

\section{Discussion}

The results of this study provide support for the hypothesis that occupational exposure to EMFs is associated with an increased risk of suicide. Men employed as electricians, and to a lesser extent as linemen, seemed to be at increased risk, broadly consistent with indications of increases in diagnosed depression and several depressive symptoms in electricians. ${ }^{37}$ Power plant operators, however, did not show increased risks. This discrepancy in results could be partially explained by a variation in exposure to levels or patterns of EMFs between those groups. Assessment of exposure to magnetic fields by Kromhout et $a l^{28}$ showed highest exposures for electricians $(1.11 \mu \mathrm{T})$ compared with linemen $(0.65 \mu \mathrm{T})$ and power plant operators $(0.79 \mu \mathrm{T})$. Also, the inconsistent findings across these jobs could be explained by varying exposure levels of other components of EMFs, which were not captured by our technique of assessing exposure. For example, Armstrong et $a l^{38}$ reported high potential exposure to pulsed electromagnetic fields (PEMFs) for linemen, moderate exposure to PEMFs for electricians, and low exposure to PEMFs for power plant operators.

As expected, men currently in work had a substantially decreased risk of suicide, which reflected the healthy worker effect. ${ }^{36}$ The increased OR for being out of work indicates that active workers are more physically and mentally fit than those who left the industry and therefore tend to have a lower risk of committing suicide. Exposure to sunlight at the workplace seemed to have a small positive association with risk of suicide, inconsistent with previously reported findings of an association of suicide with decreased exposure to sunlight. ${ }^{32-34}$ Nevertheless, a mechanism of action of light on suicide could involve inhibition of melatonin synthesis as light has an acute suppressing effect of melatonin synthesis in humans. ${ }^{39}$ The higher risk of suicide for workers living in the western United States is consistent with historical trends. ${ }^{34}$

An association of suicide with exposure to EMFs was first suggested by Reichmanis et al. ${ }^{40}$ Results indicated that the calculated strengths of EMFs at the residences of suicide victims differed from those at the residences of controls. Perry et $a l^{41}$ measured magnetic fields and found that the strength of magnetic fields was greater at addresses of those who committed suicide than at addresses of controls. However, other studies did not confirm the findings of these two initial reports. In a study of mortality of people resident in the vicinity of electricity transmission facilities, $\mathrm{McDowall}^{42}$ followed up 8000 people and found a standard-

Table 4 Adjusted * conditional logistic regression ORs (95\% CIs) for suicide relative to cumulative exposure to magnetic fields, for workers in different age groups

\begin{tabular}{|c|c|c|c|c|c|c|c|c|c|}
\hline \multirow{2}{*}{$\begin{array}{l}\text { Exposure level } \\
\text { (percentile) }\end{array}$} & \multicolumn{3}{|c|}{ Age $<35$} & \multicolumn{3}{|c|}{ Age 35-49 } & \multicolumn{3}{|c|}{ Age $\geqslant 50$} \\
\hline & Cases & Controls & OR $(95 \% C I)$ & Cases & Controls & OR $(95 \% C I)$ & Cases & Controls & OR $(95 \% C I)$ \\
\hline \multicolumn{10}{|c|}{ Recent exposuret: } \\
\hline 0 & 38 & 341 & 1.00 & 86 & 527 & 1.00 & 170 & 1485 & 1.00 \\
\hline$>0-49$ & 39 & 431 & $2.12(0.98$ to 4.59$)$ & 41 & 651 & $2.40(1.04$ to 5.55$)$ & 46 & 574 & $0.67(0.32$ to 1.42$)$ \\
\hline$\geqslant 50$ & 39 & 398 & $2.39(1.00$ to 5.69$)$ & 43 & 517 & $3.62(1.41$ to 9.29$)$ & 34 & 424 & $0.72(0.32$ to 1.62$)$ \\
\hline \multicolumn{10}{|c|}{ Past $1-5$ years $\ddagger$ : } \\
\hline 0 & 24 & 210 & 1.00 & 73 & 457 & 1.00 & 125 & 1190 & 1.00 \\
\hline$>0-49$ & 49 & 544 & 1.20 (0.63 to 2.27$)$ & 48 & 674 & 1.48 (0.84 to 2.62$)$ & 75 & 764 & 1.35 (0.86 to 2.11$)$ \\
\hline$\geqslant 50$ & 43 & 416 & $1.50(0.72$ to 3.10$)$ & 49 & 564 & $2.19(1.12$ to 4.28$)$ & 50 & 529 & $1.48(0.88$ to 2.49$)$ \\
\hline
\end{tabular}

^Adjusted for the effects of work (in work or out of work), social class, location in USA (east or west), exposure to solvents and sunlight. $\dagger 50$ Percentile $0.07,0.08$, and $0.05 \mu \mathrm{T}$-years for age $<35,35-49$, and $\geqslant 50$, respectively.

$\$ 50$ Percentile $0.20,0.21$, and $0.22 \mu \mathrm{T}$-years for age $<35,35-49$, and $\geqslant 50$, respectively. 
ised mortality ratio (SMR) of 75 on eight cases. Baris and Armstrong ${ }^{43}$ found no increased rate of suicide in men with occupations likely to have resulted in exposure to electric and magnetic fields. In another study, Baris $e t a l^{44}$ found some evidence for an association with cumulative exposure to the geometric mean (GM) of electric fields among electric utility workers, but considered the evidence for a causal association to be weak. Kelsh and Sah ${ }^{45}$ found a consistent association of suicide with nonoffice occupations in the electric utility workforce. Johansen and Olsen ${ }^{46}$ found, on the basis of 133 observed cases, no indication of excess mortality from suicide as a result of exposure to $50 \mathrm{~Hz}$ magnetic fields. None the less, all studies on suicide and EMFs have been limited in quality of assessment of exposure, sample size, or information on confounding factors.

Wilson ${ }^{5}$ postulated that long term exposure to EMFs may affect pineal function by interfering with tonic aspects of neuronal input to the pineal gland from the central nervous system, and that this disruption of normal circadian rhythmicity, particularly in synthesis of melatonin, may in turn contribute to depressive symptoms. In the present study, an association was found with cumulative exposure in the calendar year before the year of death, which can be considered to be long term exposure rather than recent exposure in the context of Wilson's hypothesised mechanism. ${ }^{5}$ High exposure to EMFs may cause depression, which, as an intermediate variable, may lead to problems at work - for example, calling in sick more often or changing jobs - or even stopping work (and thereby stopping exposure) before suicide occurs. Consequently, lower exposure levels in the intervals shortly before death may not reflect any causal effect of exposure.

Exposure to EMFs may alter melatonin secretion within days or weeks, supported by studies of users of electric blankets, ${ }^{6}$ and railway and electric utility workers. ${ }^{78}$ Consequently, depressive symptoms and related problems may develop in the months between recent exposure and suicide. Although recent exposure showed notable increases in risk, if it had been possible to ascertain exposures closer to time of death, such exposures may have shown a stronger association. Studies capable of resolving exposure and its effects over weeks or months would be informative.

An association between recent exposure to $\mathrm{EMF}$ and suicide was found in younger but not older workers, suggesting that younger people may be more vulnerable to the effects of exposure to EMFs. A difference in the nature of depression and suicide between age groups may account for this increased vulnerability. Depression can be subdivided into two categories: minor and major depression. The most important risk factor for minor depression, which is common and important in later life, seems to be medical illness. Major depression was found not to be associated with physical health ${ }^{47}$ and is more common among younger age groups. ${ }^{21}$ The change in the nature of depression with age suggests that people at younger age may be more vulnerable to the effects of exposure to EMFs causing depressive disorders and suicide.

The results of this study must be interpreted with recognition of the limitations of use of job titles to estimate exposure to EMFs over decades of work experience. Job titles explain only a small proportion of variability in exposure, as diversity across multiple work environments, electric utility companies, job tasks, and responsibilities contribute to the total variation in exposure to EMFs. ${ }^{48}$ Also, the component of EMFs that may be relevant to biological effects remains uncertain, ${ }^{49} 50$ and the current techniques for assessment of exposure to EMFs which focus on time weighted average magnetic fields can only be considered to be crude measures. Nevertheless, assessment of exposure to EMFs used in our study is more thorough than in most previous epidemiological studies on this topic.

An advantage over previous studies is the relatively large sample size, which made it possible to examine individual jobs and stratify by age. Furthermore, our ability to reproduce well known associations with work status and location in the United States was encouraging. Finally, it is unlikely that misclassification of cases has occurred. Moyer $e t a l^{51}$ examined the agreement between death certificates for causes of death related to injury and an independent medical review of medical and legal records for deaths occurring among United States Army Vietnam war veterans. Sensitivity for broad and specific suicide categories was over $90 \%$, whereas specificity was $100 \%$. This indicates that the use of death certificates is a valid method for classifying suicides. On the other hand, we were unable to isolate suicide deaths mediated by depression from other suicides, including those related to chronic disease, for which the exposure under study would not be relevant.

An important limitation was the inability to fully examine and control for confounding. Information on several important risk factors for suicide was not available - such as history of mental and addictive disorders and disrupted family environment. Nevertheless, there is some evidence that electrical workers and nonelectrical workers are generally similar in sociodemographic and related attributes, and tend to drink less alcohol than other workers. ${ }^{37}$ Also, a study by Baris et $a l^{44}$ showed similar exposure among alcohol users compared with non-users. The same study, however, showed higher exposure among single workers and workers with mental disorders ${ }^{44}$ so that the lack of adjustment for confounding by marital status and mental disorders could have led to overestimation of an association. Whether these results are applicable to the present study population is unclear. Nevertheless, it seems unlikely that confounding by unmeasured factors or imprecise measurement on the others has occurred in a sufficient degree to create or mask sizable associations.

\section{Conclusion}

In conclusion, the results of this study provide evidence for an association between cumulative exposure of extremely low frequency electro- 
magnetic fields and suicide, especially among younger workers. We hypothesise that an increased vulnerability at younger ages may be based on a change in the nature of depression with age, with suicide more closely linked to depression among younger workers and physical impairments among older workers. Future research on the effects of exposure to EMFs on suicide and depression is warranted to examine more closely the temporal pattern of exposure, depression, and suicide.

This study was supported by contract RP-2964-05 from the Electric Power Research Institute (EPRI), Palo Alto, California.
We acknowledge the substantial contribution to the conduction We acknowledge the substantial contribution to the conduction
and analysis of the study of the following people: University of and analysis of the study of the following people: University of
North Carolina colleagues Michael Flynn, Lawrence Kupper, North Carolina colleagues Michael Flynn, Lawrence Kupper,
Stephen Rappaport, and Lori Todd; Hans Kromhout of WageStephen Rappaport, and Lori Todd; Hans Kromhout of Wageningen Agricultural University in The Netherlands; research assistants Stephen Browning, Kevin Chen, Gary Mihlan, Lucy Peipins, and Sandy West; and computer programmers Richard Howard, Eileen Gregory, and Joy Wood. EPRI Scientific Advisors A A Afifi, Patricia Buffler, James Quackenboss, T Dan Bracken, Gary Marsh, and Thomas Smith. Collaborating contractors J Michael Silva and Richard Iriye of Enertech Consultants, William Kaune of EM Factors, Margaret Pennybacker of Battelle, and Survey Research Associates Judy Rayner of Westat, and William West. Also, many electric utility employees from Carolina Power and Light, Pacific Gas and Electric, PECO from Carolina Power and Light, Pacific Gas and Electric, PECO Energy Company (formerly Philadelphia Electric Company),
Tennessee Valley Authority, and Virginia Electric Power Tennessee Valley Authority, and Virginia Electric Power
Company, devoted a substantial amount of time assisting us with many aspects of the study, lending their expertise, time, and patience, for which we are most appreciative.

1 Singh GK, Kochanek KD, MacDorman MF. Advance report of final mortality statistics, 1994 . Monthly vital statistics report
45(3), suppl. Hyattsville, MD: National Center for Health 45(3), suppl. Hyat

2 Centers for Disease Control and Prevention. Years of potential life lost before age 65: United States, 1990 and 1991. MMWR Morb Mortal Wkly Rep 1993;42:251-3.

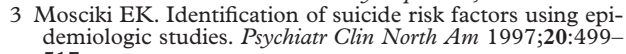
517.

4 Monk M. Epidemiology of suicide. Epidemiol Rev 1987;9: 51-69.

5 Wilson BW. Chronic exposure to ELF fields may induce depression. Bioelectromagnetics 1988;9:195-205.

6 Wilson BW, Wright CW, Morris JE, et al. Evidence for an effect of ELF electromagnetic fields on human pineal gland function. F Pineal Res 1990;9:259-69.

7 Pluger DH, Minder CE. Effects of exposure to $16.7 \mathrm{~Hz}$ magnetic fields on urinary 6-hydroxymelatonin sulfate excretion of Swiss railway workers. F Pineal Res 1996;21: 91-100.

8 Burch JB, Reif JS, Yost MG, et al. Nocturnal excretion of a urinary melatonin metabolite among electric utility workers. Scand $\mathcal{F}$ Work Environ Health 1998;24:183-9.

9 Brown RP, Kocsis JH, Caroff S, et al. Depressed mood and reality disturbance correlate with decreased nocturnal melatonin in depressed patients. Acta Psychiatr Scand 1987;76:272-5.

10 Wetterberg L, Aperia B, Gorelick DA, et al. Age, alcoholism and depression are associated with low levels of urinary melatonin. F Psychiatry Neurosci 1992;17:215-24.

11 Beck-Friis J, Kjellman BF, Aperia B, et al. Serum melatonin in relation to clinical variables in patients with major depressive disorder and a hypothesis of a low melatonin syndrome. Acta Psychiatr Scand 1985;71:319-30

12 Nair NP, Hariharasubramanian N, Pilapil C. Circadian rhythm of plasma melatonin in endogenous depression.
Prog Neuropsychopharmacol Biol Psychiatry 1984;8:715-8.

13 Poole C, Kavet R, Funch DP, et al. Depressive symptoms and headaches in relation to proximity of residence to an alternating-current transmission line right-of-way. $\mathrm{Am}$ Epidemiol 1993;137:318-30.

14 Verkasalo PK, Kaprio J, Varjonen J, et al. Magnetic fields of transmission lines and depression. Am $\mathcal{F}$ Epidemiol 1997; 146:1037-45.

15 Beale IL, Pearce NE, Conroy DM, et al. Psychological effects of chronic exposure to $50 \mathrm{~Hz}$ magnetic fields in humans living near extra-high-voltage transmission lines. Bioelectromagnetics 1997;18:584-94.

16 Perry S, Pearl L, Binns R. Power frequency magnetic field; depressive illness and myocardial infarction. Public Health 1989;103:177-80

17 Dowson DI, Lewith GT, Campbell M, et al. Overhead highvoltage cables and recurrent headache and depressions. Practitioner 1988;232:435-6.

18 Bonhomme-Faivre L, Marion S, Bezie Y, et al. Study of human neurovegetative and hematologic effects of environmental low-frequency $(50-\mathrm{Hz})$ electromagnetic fields produced by transformers. Arch Environ Health 1998;53: 87-92.

19 Savitz DA, Loomis DP. Magnetic field exposure in relation to leukemia and brain cancer mortality among electric utility workers. Am F Epidemiol 1995;141:123-34.
20 Karel MJ. Aging and depression: vulnerability and stress across adulthood. Clin Psychol Rev 1997;17:847-79.

21 Sullivan MD. Maintaining good morale in old age. West $\mathcal{f}$ Med 1997;167:276-84.

22 Greenland S, Thomas DC. On the need for the rare disease assumption in case-control studies. Am $\mathcal{F}$ Epidemiol 1982;116:547-53.

23 Rothman KJ. Greenland S. Case-control studies. In: Rothman KJ, Greenland S, eds. Modern epidemiology. Philadelphia: Lippincott-Raven Publishers, 1998:93-114.

24 Valberg PA. Designing EMF experiments: what is required to characterize "exposure"? Bioelectromagnetics 1995;15: 396-401

25 Villeneuve PJ, Agnew DA, Corey PN, et al. Alternate indices of electric and magnetic field exposures among Ontario electrical utility workers. Bioelectromagnetics 1998;19:149-51

26 Loomis DP, Peipins LA, Browning SR, et al. Organization and classification of work history data in industry-wide studies: an application to the electric power industry. $A m \mathcal{F}$ Ind Med 1994;26:413-25.

27 Loomis DP, Kromhout H, Peipins LA, et al. Sampling design and methods of a large, randomized, multi-site survey of occupational magnetic field exposure. Applied Occupational and Environmental Hygiene 1994;9:49-52.

28 Kromhout H, Loomis DP, Mihlan GJ, et al. Assessment and grouping of occupational magnetic field exposure in five electric utility companies. Scand $\mathcal{f}$ Work Environ Health 1995;21:43-50.

29 Ferrada-Noli $M$. Health and socioeconomic indicators in psychiatric catchment areas with divergent suicide rates. Psychol Rep 1997;81:611-9.

30 Lampert DI, Bourque LB, Kraus JF. Occupational status and suicide. Suicide Life Threat Behav 1984;14:254-68.

31 Berlin K, Edling C, Persson B, et al. Cancer incidence and mortality of patients with suspected solvent-related disorders. Scand F Work Environ Health 1995;21:362-7.

32 Preti A. The influence of climate on suicidal behaviour in Italy. Psychiatry Res 1998;78:9-19.

33 Linkowski P, Martin F, De Maertelaer V. Effect of some climatic factors on violent and non-violent suicides in Belgium. F Affect Disord 1992;25:161-6.

34 Tietjen GH, Kripke DF. Suicides in California (19681977): absence of seasonality in Los Angeles and Sacramento counties. Psychiatry Res 1994;53:161-72.

35 Loomis D, Browning SR, Schenck AP, et al. Cancer mortality among electric utility workers exposed to polychlorinated biphenyls. Occup Environ Med 1997;54: $720-8$.

36 Steenland K, Stayner L. The importance of employment status in occupational cohort mortality studies. Epidemiology 1991;2:418-23.

37 Savitz DA, Boyle CA, Holmgreen P. Prevalence of depression among electrical workers. Am f Ind Med 1994; 25:165-76.

38 Armstrong B, Thériault G, Guenel P, et al. Association between exposure to pulsed electromagnetic fields and cancer in electric utility workers in Québec

39 Delagrange P, Guardiola-Lemaitre B. Melatonin, its receptors, and relationships with biological rhythm disorders. Clin Neuropharmacol 1997;20:482-510.

40 Reichmanis M, Perry FS, Marino AA, et al. Relation between suicide and the electromagnetic field of overhead power lines. Physiological Chemistry and Physics 1979;11: 395-403.

41 Perry FS, Reichmanis M, Marino AA, et al. Environmental power-frequency magnetic fields and suicide. Health Phys 1981;41:267-77.

$42 \mathrm{McD}$ owall ME. Mortality of persons resident in the vicinity of electricity transmission facilities. Br $\mathcal{F}$ Cancer 1986;53: 271-9.

43 Baris D, Armstrong B. Suicide among electric utility workers in England and Wales [letter]. $\mathrm{Br} F$ Ind Med 1990;47:788-92.

44 Baris D, Armstrong BG, Deadman J, et al. A case cohort study of suicide in relation to exposure to electric and magnetic fields among electric utility workers. Occup Environ Med 1996;53:17-24.

45 Kelsh MA, Sahl JD. Mortality among a cohort of electric utility workers, 1960-91. Am F Ind Med 1997;31:534-44.

46 Johansen C, Olsen JH. Mortality from amyotrophic lateral sclerosis, other chronic disorders, and electric shocks among utility workers. Am $\mathcal{7}$ Epidemiol 1998;148:362-8.

47 Beekman AT, Penninx BW, Deeg DJ, et al. Depression and physical health in later life: results from the longitudinal aging study Amsterdam (LASA). F Affect Disord 1997;46: 219-31.

48 Kelsh MA, Kheifets L, Smith R. The impact of work environment, utility, and sampling design on occupational magnetic field exposure summaries. Am Ind Hyg Assoc $\mathcal{F}$ (in press).

49 Portier CJ, Wolfe MS, eds. Assessment of health effects from exposure to power line frequency electric and magnetic fields: working group report. Research Triangle Park, NC: National Publ No 98-3981.)

50 Valberg PA. Electric and magnetic fields (EMF): what do we know about the health effects? Int Arch Occup Environ Health 1996;68:448-54.

51 Moyer LA, Boyle CA, Pollock DA. Validity of death certificates for injury-related causes of death. Am $\mathcal{F}$ Epidemiol 1989;130:1024-32. 